\title{
Exploration of the Correlation between Relationship Network and International Entrepreneurship Performance
}

\author{
Jin $\mathrm{Wu}$ \\ Business School, Nanfang College of Sun Yat-Sen University. \\ ruojincn@126.com
}

\begin{abstract}
In order to arouse the importance of foreign enterprises and our government to create a good entrepreneurial environment, the relationship between the relationship network and the performance of the international enterprise is discussed from the perspective of the resource theory. First, the measurement dimensions of each research object are divided, and on this basis, a conceptual model of the relationship between the relationship network and the performance of the international enterprise based on the theory of resource outlook is proposed. Then, an international integration framework of entrepreneurship research is constructed, including the pre-variable, the independent variable, the intermediary variable, the dependent variable and the adjustment variable. On the basis of clarifying the relationship between the research objects, three hypotheses are put forward. Finally, the empirical analysis is used to verify the experimental results. The experimental results show that the three assumptions are all established, and the relationship network has a positive promoting effect on the availability of resources. Moreover, there is a positive correlation between resource availability and the improvement of the performance of international entrepreneurs, and the ability of resource integration has a positive regulating effect on the relationship between resource availability and the performance of international entrepreneurial enterprises.
\end{abstract}

Keywords: Relationship network, international entrepreneurial performance, resource availability, resource integration capability.

\section{Introduction}

In the research on the relationship network, most scholars believe that network connections will affect the performance of individuals and organizations. Through the statistical discovery of the literature on entrepreneurship research in recent years, it is found that the importance of the relationship network to the process of entrepreneurship has been reflected in more and more models and studies. The establishment of personal relationship network and the motivation of establishing relationship network have become a problem that many related scholars have paid close attention to in recent years. At the same time, the organizational network in the relationship network is becoming more and more important in international entrepreneurship research. The relationship network can provide a fast channel for the international enterprises to obtain the resources that its own development needs from the external environment. In other words, it plays a "bridge" role for enterprises to obtain external resources.

The relationship network is defined as the mutual contacts between the international business enterprise and the relevant institutions in the external environment. In the meanwhile, the relationship network, as the research object, is an important way for the international enterprise to obtain the relevant information and key resources. The development of the international business enterprise cannot be separated from the organization subject in the outside environment that provides the information and resources. Only establishing different relationships with the organizational subjects can it establish a good relationship network and finally get the resources it needs. In this way, it can strengthen the exchanges with the object of production service, the competitors of the same industry, the cooperation partners with business contacts and the government organizations. It has a great effect on promoting the exchange of knowledge and information between the organization subjects, and provides more resources for the enterprises to develop. It has a certain guiding significance for the relevant government departments to formulate policies to improve the entrepreneurial environment, which is conducive to the establishment and development of international entrepreneurial enterprises in China. 


\section{State of the Art}

International entrepreneurship is a kind of small-scale enterprise which takes advantage of international market or resources to gain international competitive advantage and devotes itself to international business activities (Venkatraman and Kayak, 2014). International entrepreneurship is a kind of innovative behavior and entrepreneurial activity, and this behavior and activity is based on the company level. New ventures and mature enterprises are the object of international entrepreneurship research (Bagger, Geiger, Segerstrom and Carlson, 2015). International entrepreneurship is a kind of behavior that creates value through the acquisition and integration of resources in many countries, and the subjects of international entrepreneurship include not only new ventures but also mature enterprises (Russell, Bode Nan, Starkey, Jeffries, Kearse, and Spratt, 2017). Generally speaking, the concept of relational network mainly contains two meanings. First, international entrepreneurs attempt to overcome high market transaction costs through the relationship network. Second, because the various resources needed by international entrepreneurs cannot be fully provided by them, in the case of accomplishing the task and no enough resources for them to use, the international business enterprise must be able to obtain the help of the external environment subject in resources to overcome the lack of resources (AL Hakeem, Abitibi, Malherbe and Khan, 2014). Relational networks can be defined as "network connections established between international entrepreneurs and external environmental entities" (Reddy, 2015). The research on the network is divided into two kinds. One is to study the network from the connotation and form; the other regards the network as an analytical tool to describe and explain a variety of complex social phenomena and the possible underlying causes of these phenomena (Tsvetkova and Partridge, 2017). At present, there are two classification methods for relationship networks: one is formal network and informal network, and the other is to divide the relationship network into individual network and organizational network according to the difference of subjects (Marvel and Wolfe, 2015). International entrepreneurs acquire information and knowledge through the relationship network, so that they can more accurately excavate and utilize these opportunities in the overseas market, thus strengthening the contacts between international entrepreneurs and the various organizations that have business contacts (Cao and Anderson, 2016). The factors influencing the internationalization process of relational networks are mainly discussed in terms of network strength, network scale and network density (Tafoya, 2016). The connection strength of the relationship network is expressed by strong and weak. The heterogeneity of information obtained through strong relations is low and most of them are heavy information, and the information heterogeneity obtained through weak relations is high, so the weak relationship is an important source for information acquisition (Narayanan and Lévesque, 2014).

\section{Method}

\subsection{Measure of Variable}

There are four variables to be measured, and they are the relationship network, the availability of the enterprise resources, the ability to integrate the resources within the enterprise and the performance of the international enterprise, respectively.

The measurement of relationship networks: it is the relationship formed between international entrepreneurial enterprises as the subject of organization and the subject of external environment. By summarizing the measurement of the network at home and abroad, it is found that most of the studies focus on the coverage of the network, the tightness, intensity and diversity of the network and so on variables. The network trend, the network density, the network flexibility and the network's non-fixity are the major features of the network. At the same time, the relationship network also shows some structural features, and it is divided into three levels - network coverage, density and order. The view of Sawyer and McGee is referred to, and the measurement of relationship network can be considered from the aspect of intensity. For example, the relationship network can be expressed by the strength of the relationship between the enterprise and the subject in the external environment. Likert's five- 
level scoring method is used to measure the strength of the international entrepreneurial relationship network through five items. They are: the degree of intercourse with intermediaries; the degree of contact with the government organizations; the degree of contacts with customers and consumers; the degree of contact with the suppliers of raw materials; the close degree of establishing contact with the partners.

The measurement of the acquisition degree of enterprise resources: starting from the perspective of the demand for resources by international enterprises, a scale development of the resource acquisition degree of international enterprise is carried out. It is believed that the acquisition degree of international enterprise resources can be measured from two aspects. One is the number of resources can be obtained based on the needs of the enterprise's own resources, and the other is the smooth degree of resource acquisition channels. Based on the existing research, the Likert's five-level scoring method is used to measure 4 items, and they are: the amount of technology, funds and talents can be obtained; the information and knowledge can be obtained; the required technology, funds and talents can be obtained from different channels; the required information and knowledge can be obtained from different channels.

The measurement of resource integration capability: the internal resource integration capability is expressed from the perspectives of resource combination capability and resource utilization efficiency. The resource combination capability of an enterprise can be expressed in two ways: one is to combine the existing resources, and the other is to integrate new resources with existing resources. Combined with the existing research situation, the Likert's five-level scoring method is used to measure through 4 items, respectively: enterprises can combine the existing resources; enterprises can integrate new and old resources together; enterprises can effectively regulate the combination of resources; enterprises can effectively and efficiently use resources.

The measurement of the performance of international entrepreneurial enterprises: the performance of international entrepreneurial enterprises is mainly measured from two aspects, one is based on the perspective of income and development, and the other is based on the perspective of creation and growth.

On the basis of the above measurement analysis, a relatively comprehensive conceptual model is constructed. The conceptual model clearly shows the relationship between the various research objects, as shown in Figure 1.

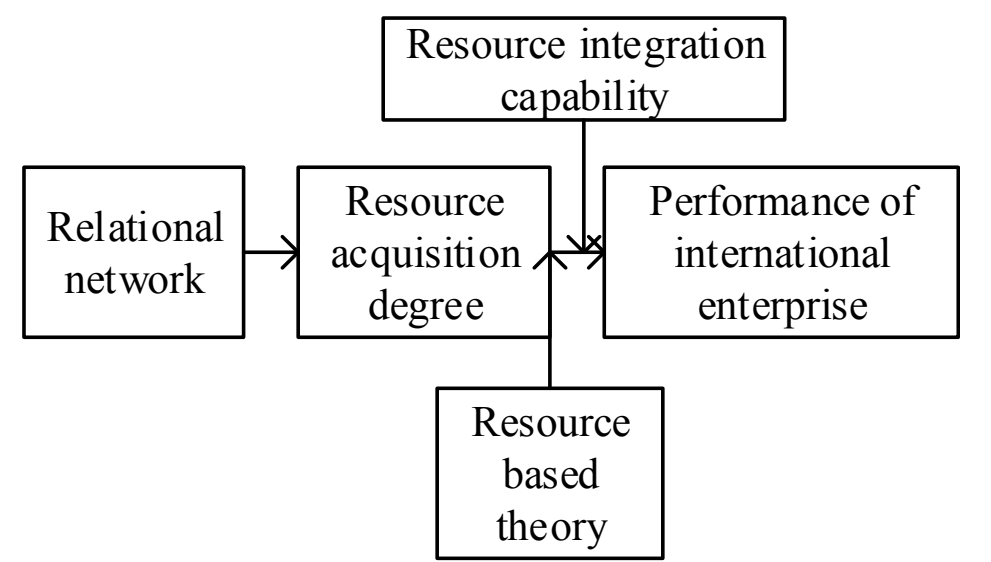

Figure 1. The relationship between the various research objects

The research structure mainly includes the following three parts: first, the relationship between relationship network and resource availability; second, the relationship between resource availability and international entrepreneurial performance; third, the adjustment influence of resource integration capability on the relationship between resource availability and the performance of international entrepreneurial enterprises. 


\subsection{Construction of International Business Relationship Network}

In the field of relationship network research, scholars mainly divide the types of network relationships based on the characteristics of network relations, as shown in Table 1. However, international entrepreneurship researchers directly adopt the method that relational network researchers use to define the relational networks.

Table 1. Summary of different types of relationship network related research

\begin{tabular}{|c|c|c|}
\hline Division basis & Relationship network type & Author (year) \\
\hline Gradation & $\begin{array}{l}\text { The interpersonal relationship network and } \\
\text { the organization relationship network; } \\
\text { The social relationship network and business } \\
\text { relationship network; } \\
\text { The domestic relationship network and } \\
\text { international relationship network. }\end{array}$ & $\begin{array}{c}\text { Johansson and } \\
\text { Mattson (1988), } \\
\text { Easton and Hakansson (1996), } \\
\text { Burt (2000) }\end{array}$ \\
\hline $\begin{array}{l}\text { Relationship } \\
\text { strength }\end{array}$ & $\begin{array}{l}\text { Strong relationship; } \\
\text { Weak relationship. }\end{array}$ & $\begin{array}{c}\text { Granovetter (1973), } \\
\text { Soderqvist and Chetty (2009), } \\
\text { Prashantham and Young (2011) }\end{array}$ \\
\hline Network structure & $\begin{array}{l}\text { Subordinate position; } \\
\text { Center position. }\end{array}$ & Wasserman and Faust (1994) \\
\hline Generation form & $\begin{array}{l}\text { Active networking; } \\
\text { Passive networking. }\end{array}$ & Johanson and Mattsson (1988) \\
\hline $\begin{array}{l}\text { Resource-based } \\
\text { view }\end{array}$ & $\begin{array}{l}\text { Structural social capital; } \\
\text { Relational social capital; } \\
\text { Cognitive social capital. }\end{array}$ & $\begin{array}{l}\text { Nahapiet and Ghoshal (1998), Lin et al. } \\
\text { (2001), and Prashantham (2008) }\end{array}$ \\
\hline
\end{tabular}

On the basis of combing the relevant literature, it is found that the strategy of establishing the international entrepreneurial relationship network can be summed up as five strategies. They are the direct transformation of social relationship into business relationship, the recommendation of business or social relationship, the trade fair, the advertising-based and the formal goals. At present, scholars are also keen to explore the specific strategies constructed for the international entrepreneurial relationship networks. But, it is necessary to notice that constructing different types of relationship networks need to take different strategies. Therefore, it is necessary for the future research to discuss which strategy the entrepreneurs or international entrepreneurial enterprises should use in order to build a specific type of network relationship (such as strong business relationship or weak business relationship).

There are many factors influencing the construction of international entrepreneurial relationship network, but they can be roughly divided into subjective factors related to entrepreneurs and objective factors related to institutional environment. In terms of subjective factors, recent studies show that entrepreneurs' relationship knowledge and competence have an important impact on the construction of international entrepreneurial relationship networks. In terms of objective factors, the existing research shows that the factors that affect the establishment of the international entrepreneurial relationship network are mainly the institutional environment of the home country and the institutional distance between the home country and the host country.

\subsection{Empirical Analysis}

First of all, three assumptions are put forward: first, the relation network is positively related to the availability of resources; second, the acquisition degree of resources is positively related to the performance of the international enterprise; and third, the stronger the ability of resource integration within the enterprise is, the greater the effect of resource acquisition on the performance of international entrepreneurial enterprises is.

According to the characteristics of the research objects, the random system sampling method is used to sample the sub-companies of multinational corporations in China in three regions of Jiangsu, Chongqing and Beijing. Of the 1000 questionnaires issued, 452 valid questionnaires are retrieved, 
accounting for more than $40 \%$ of the total. This ratio fully meets the requirements of the research. A descriptive analysis of the basic characteristics of the total sample of the establishment time, the number of employees, the major categories of the industry, and the location of the company is carried out. Finally, according to the view of Jailor and Martinez, for a real foreign company, at least $50 \%$ of the shares will be controlled by foreign capital. The enterprises with foreign capital holdings lower than $50 \%$ will be eliminated from these 452 enterprises, and at last, 124 foreign-funded enterprises are remained. The time of establishment, the number of employees, the major categories of the industry, and the location of the company, are analyzed in detail.

In order to eliminate the possible multi- collinearity between variables, factor analysis of related variables should be carried out before structural equation model analysis. According to the general principle of factor analysis, the factor load of each determinant of the coercive factor analysis should be greater than 0.7 , and the factor load of each measurement variable in the exploratory factor analysis should be greater than 0.5 . The reliability analysis of the relationship network, resource availability, resource integration capability and the performance of international enterprise is carried out. The results show that the factor variables used are all in line with the requirements.

For the fitting of the whole model, several specific indexes with good stability are selected as the evaluation of the model based on the estimation method adopted.

The first is the absolute fitting index, where the fitting goodness chi square $(\mathrm{x} 2)$ and $\mathrm{x} 2=(\mathrm{n}-1) \mathrm{F}$ and $\mathrm{F}$ represents the fitting function. There are $\mathrm{x} 2=86.192$ of the model, and the freedom degree is 58. In general, for the established significant level, if the $\mathrm{x} 2$ value is larger than the corresponding critical value, then it can be considered that the fitting degree between the model and the data is not good. Conversely, if the $x 2$ value is less than the corresponding critical value, then it can be considered that the fitting degree between the model and the data is good.

The mathematical expression of the goodness of fitting index (GFI) is as follows:

$$
G F I=\frac{F\left(S, \sum(\theta)\right)}{F\left(S, \sum(0)\right)}
$$

In Formula (1), the molecule represents the numeric value of the model fitting function, and the denominator represents the fitting function value of the independent model. The result of the test shows that the GFI value of the model is 0.972 , more than 0.9 , and very close to 1 , so a good model fitting can be obtained.

The overall fitting test of the model is shown in Table 2.

Table 2. The overall fitting test of the model

\begin{tabular}{|c|c|c|}
\hline Fitting index & Index value & Fitting situation \\
\hline Goodness of fit chi square test x2 & 84.25 & \\
\hline Freedom & 56 & Greater than 0.05 , meeting the requirements. \\
\hline Absolute fitting index $\mathrm{p}$ & 0.11 & Between $1-3$, very good. \\
\hline $\mathrm{x} 2 /$ do & 1.324 & Greater than 0.9 and close to 1, very good. \\
\hline Goodness of fit index GFI & 0.974 & Greater than 0.9, very good. \\
\hline Modified goodness of fit index (AGFI) & 0.906 & Smaller than 0.05, very good. \\
\hline Root mean square error approximation (RMSEA) & 0.036 & Greater than 0.9, very good. \\
\hline Non-normalization fitting index (TLI) & 0.978 & Greater than 0.9, very good. \\
\hline Normalized fitting index (NFI) & 0.91 & Greater than 0.9, very good. \\
\hline Corresponding fitting index (CFI) & 0.95 & \\
\hline
\end{tabular}

The test results assumed are shown in Table 3 and Figure 2.

First, the impact of relationship network on resource availability is analyzed. In the test results, the correlation coefficient between the two is 0.245 and $p=0.047$ less than 0.1 . It indicates that, assuming that the hypothesis passes the verification, in line with the expectation, this shows that relationship networks have a positive impact on resource availability, and strengthening the maintenance of relational networks can improve resource availability. 
Second, the impact of resource availability on the performance of international entrepreneurial enterprises is discussed. In the test results, the correlation coefficient between the two is 0.277 and $p=0.001$ less than 0.01. It indicates that the hypothesis passes the verification and is consistent with expectations, suggesting that the easier the international business enterprise is to obtain the resources it needs, the better the performance of the international enterprise will be.

Third, resource integration capability moderates the relationship between resource availability and the performance of international entrepreneurial enterprises. The test results show that the correlation coefficient between the two is 0.193 and the $p=0.002$ less than 0.01 . It can be verified and consistent with the expectation. This shows that the stronger the enterprise's ability to integrate resources is, the greater the performance will be under the circumstances of the established resources.

Table 3. The overall situation of the hypothesis test

\begin{tabular}{|c|c|c|c|c|}
\hline $\begin{array}{c}\text { Hypothesis } \\
\text { number }\end{array}$ & Hypothesis description & $\begin{array}{c}\text { Standard regression } \\
\text { coefficient / } \\
\text { correlation } \\
\text { coefficient }\end{array}$ & $\mathrm{P} / \mathrm{sig}$ & Test results \\
\hline 1 & $\begin{array}{c}\text { The relationship network is positively } \\
\text { related to the availability of resources. }\end{array}$ & 0.245 & 0.047 & Supported \\
\hline 2 & $\begin{array}{c}\text { The resource availability is positively } \\
\text { related to the performance of } \\
\text { international entrepreneurial enterprises. }\end{array}$ & 0.277 & 0.001 & Supported \\
\hline $\begin{array}{c}\text { The stronger the ability of resource } \\
\text { integration is, the stronger the impact of } \\
\text { resource availability on the performance } \\
\text { of international entrepreneurial } \\
\text { enterprises is. }\end{array}$ & 0.193 & 0.002 & Supported \\
\hline
\end{tabular}

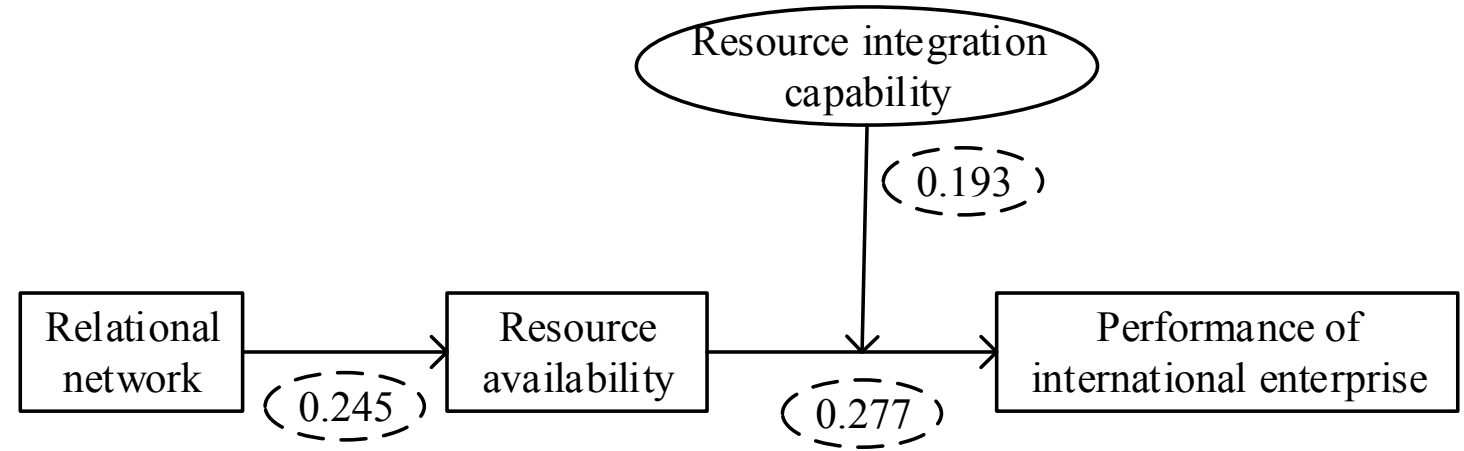

Figure 2. Hypothesis test results of structural equation theory model

\section{Results}

Hypothesis 1 is about the impact of relationship networks on the acquisition of enterprise resources. In the model, it is assumed that the relationship network is positively related to the acquisition degree of the enterprise resources. The results show that it can pass the verification and the conclusion is consistent with the relevant research conclusions. The stronger the relationship network is, the easier the enterprise to get the required resources will be.

Hypothesis 2 is the relationship between the degree of enterprise resource acquisition and the performance of international entrepreneurial enterprises. And it is assumed that the availability of enterprise resources has a positive correlation with the performance of the international enterprise. The results show that the hypothesis can be tested and the conclusion is consistent with the other research conclusions. Therefore, for international entrepreneurial enterprises, in order to achieve the ultimate value creation, possession and access to the necessary resources is a necessary condition.

Hypothesis 3 is the moderating effect of resource integration capability on the acquisition of enterprise resources and the performance of international entrepreneurial enterprises. It is assumed that the stronger the ability of resource integration within the enterprise is, the more significant the 
promoting role of the acquisition degree of the enterprise resource on the performance of the enterprise is. The results test the hypothesis, and the results are verified, and this conclusion is supported by the research conclusion of scholars in the relevant fields.

\section{Conclusion}

The intensity of the relationship network of international entrepreneurial enterprises has a positive correlation with resource acquisition. In the stage of China's transformation economy, to acquire the resources needed in their own development process, enterprises must realize it through the relationship network. Based on the special human relationship and interpersonal relationship in China, the enterprise's human relationship is the network pattern centered on the enterprise itself. Through the relationship of the difference sequence pattern, the enterprise can obtain all kinds of resources for the survival and development of the enterprise. If the enterprise has a strong relationship network, it will reduce the cost for the enterprise to acquire the resources for meeting its own development.

Resource acquisition is the prerequisite for the enterprise to get the development. No matter what strategy the enterprise develops based on, its premise is to acquire a certain quantity and quality of resources. The availability of resources affects the efficiency and effectiveness of resource acquisition, thus affecting the improvement of enterprise performance.

In the study of the core competitiveness of enterprises, scarce and imitable resources are the basis for the enterprise to maintain the core competitiveness. But only through a unique and reasonable allocation and use can the core competitiveness of the enterprise be formed. Therefore, the ability of resource integration plays a positive role in the relationship between resource availability and the performance of international entrepreneurial enterprises.

\section{References}

[1]. Venkatraman, S., \& Nayak, R. R. (2014). Hrm competencies of women entrepreneurs in network marketing: a study on the influencing factors and their relationships on success. International Journal of Indian Culture \& Business Management, 8(1), 69-106.

[2]. Boggero, I. A., Geiger, P. J., Segerstrom, S. C., \& Carlson, C. R. (2015). Pain intensity moderates the relationship between age and pain interference in chronic or facial pain patients. Experimental Aging Research, 41(4), 463-474.

[3]. Russell, S. S., Bodenan, J. D., Starkey, N. A., Jeffries, T. E., Kearsley, A., \& Spratt, J. (2017). Relationship between cais and chondrules: a case study of a compound chondrule from the Allende (cv3) meteorite. Geochemical Journal, 51(1), 31-43.

[4]. Alhakeem, M. M., Abotalib, Z., Alharbi, K. K., \& Khan, I. A. (2014). Relationship between the paraoxonase 1 gene glutamine 192 to arginine polymorphism and gestational diabetes mellitus in Saudi women. Clinical Biochemistry, 47(15), 122-5.

[5]. Reddy, B. S. (2015). Access to modern energy services: an economic and policy framework. Renewable \& Sustainable Energy Reviews, 47, 198-212.

[6]. Tsvetkova, A., \& Partridge, M. (2017). The shale revolution and entrepreneurship: an assessment of the relationship between energy sector expansion and small business entrepreneurship in us counties. Energy, 141(C), 423-434.

[7]. Marvel, M. R., Lee, I. H., \& Wolfe, M. T. (2015). Entrepreneur gender and firm innovation activity: a multilevel perspective. IEEE Transactions on Engineering Management, 62(4), 558567.

[8]. Cao, Z., \& Anderson, V. (2016). Analysis of Chinese student values and implications, for the global economy. Copies, 1934(4), 181-181. 
[9]. Tafida, A. (2016). Autocorrelational relationship between concerted effort and social capital investment on entrepreneurships growth in Africa: an empirical investigation (2005-2015). Electrophoresis, 36(5), 646-54.

[10]. Narayanan, M., \& Lévesque, M. (2014). Venture capital deals: beliefs and ownership. IEEE Transactions on Engineering Management, 61(4), 570-582. 